\title{
Study and Verification of the Parameters of a Wind Park
}

\author{
N. Angulo', A. Pulido', J. Romero', P. González', M. Melilli' J. Lozano² \\ 'Department of Electrical Engineering \\ Las Palmas de Gran Canaria University \\ Campus of Tafira, 35017 Las Palmas (Spain) \\ phone:+34 928451981, fax:+34 928421874e-mail: nangulo@die.ulpgc.es, \\ apulido@die.ulpgc.es, iromero@die.ulpgc.es, pgonzalez@die.ulpgc.es, melomiki@tiscali.it \\ ${ }^{2}$ Soslayres Canarias S.L.
}

\section{Introduction}

In the Canary Islands it is possible to take advantage of the strength of the trade winds, which blow throughout the year and especially within the summer months. The work will be based on real data taken from the Agüimes (Gran Canaria Island) power station's control centre.

\section{Power Station's Description}

The Farm is formed by four units Gamesa G47- $660 \mathrm{~kW}$, adding a power of $2.64 \mathrm{MW}$, which have been on-line since 2002 .

The Generators are doubly fed machines (DFM), whose speed and power is controlled through IGBT converters and PWM (Pulse Width Modulation) electronic control. Advantages of the electronic control of the rotor by inverter are:

A. Active and reactive power control.

B. Low harmonics content and minimum losses.

C. Increased efficiency and production.

D. Prolonged working life of the turbine.

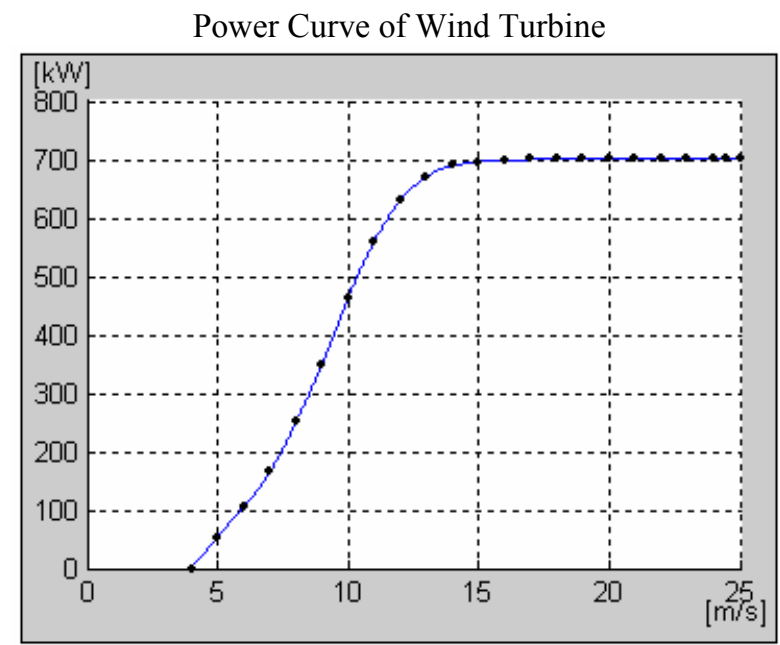

Fig. 1
The characteristics of the wind turbine are the following ones:

$$
\begin{array}{lr}
\text { Diameter. } & 47 \mathrm{~m} \\
\text { Nominal power. } & 660 \mathrm{~kW} \\
\text { Speed turn: } & 22,8 \div 30.9 \mathrm{rpm} \\
\text { Nominal voltage } & 690 \mathrm{~V} \\
\text { Nominal current } & 557,9 \mathrm{~A} \\
\text { Area of sweeping: } & 1735 \mathrm{~m}^{2}
\end{array}
$$

\section{Performances of the Plant}

The plant boast a very high capacity factor far above the average for other European wind power stations, owing to the use of Gamesa wind turbines.

$F C \%=\frac{E_{p}(K w h)}{P_{n}(K w) \cdot(8760 h)} \cdot 100$

$\mathrm{Ep}=$ Energy produced in 1 year $\mathrm{Pn}=$ Turbine nominal Power

Detailed production / Date 1/01/2003 31/12/2003

\begin{tabular}{|c|c|c|c|c|}
\hline AEROG. & Run & Gen & Producción & FC \\
\hline & (horas) & (horas) & (kWh) & $(\%)$ \\
\hline 1 & 8.381 & 7.136 & 2.817 .296 & $\mathbf{4 5 , 9 4}$ \\
\hline \hline 2 & 8.121 & 6.923 & 2.786 .964 & $\mathbf{4 5 , 4 5}$ \\
\hline \hline 3 & 8.168 & 6.964 & 2.346 .091 & 38,26 \\
\hline \hline 4 & 8.446 & 7.137 & 2.446 .220 & 39,89 \\
\hline \hline MediaReal & 8.279 & 7.040 & & $\mathbf{4 2 . 3 8}$ \\
\hline Tddies & 33.116 & 28.159 & 10.396 .571 & \\
\hline
\end{tabular}

Table 1

These wind turbines have proven a very high index of availability.

$D_{A}=\frac{T d}{T \text { line }} \cdot 100 \quad \begin{aligned} & \mathrm{Td}=\text { time of availability of the turbine } \\ & \text { Tline=time of availability of the red }\end{aligned}$ 
Detailed production / Date 1/01/2004 31/12/2004

\begin{tabular}{|c|c|c|c|c|}
\hline AEROG. & Line OK & Turbine OK & Producción & Disponibilidad \\
\hline & (horas) & (horas) & $(\mathrm{kWh})$ & $(\%)$ \\
\hline 1 & 8.027 & 7.712 & 2.237 .506 & 96,08 \\
\hline \hline 2 & 7.810 & 7.710 & 2.374 .825 & 98,72 \\
\hline \hline 3 & 7.816 & 7.726 & 1.879 .941 & 98,85 \\
\hline \hline 4 & 7.822 & 7.756 & 1.990 .699 & 99,16 \\
\hline \hline MediaReal: & 7.869 & 7.726 & & 98,19 \\
\hline Tddeses & 31.475 & 30.904 & 8.482 .971 & \\
\hline
\end{tabular}

Table 2

\section{Analysis of Real Data}

The power station's control centre allows for the measurement of more important four wind turbine mechanical and electrical parameters :

From this data, it is possible to track the working characteristics of the machines and compare that with the theoretical data:

\section{A. Electrical Power Coefficient}

$$
C_{p, e l t}=C_{p, m}(\lambda, \beta) \cdot \eta_{m} \cdot \eta_{\text {elt }}=\frac{P e}{0.5 \cdot \rho \cdot V^{3} \cdot \pi \cdot \frac{D^{2}}{4}}
$$

Where:

$$
\begin{aligned}
& \mathrm{Pe}=\text { Electrical Power } \\
& \rho=1.255\left[\mathrm{~kg} / \mathrm{m}^{3}\right] \text { air density } \\
& \mathrm{V}=\text { wind speed } \\
& \mathrm{D}=\text { diameter rotor blade }
\end{aligned}
$$

$\mathrm{C}_{\mathrm{p} \text {,elt }}$ theoretical has been calculated from the Theoretical Power Curve (Fig. 1) according to the equation (3).

$\mathrm{C}_{\mathrm{p}, \mathrm{elt}}$ real has been calculate from the real production dates of the Wind Turbine.

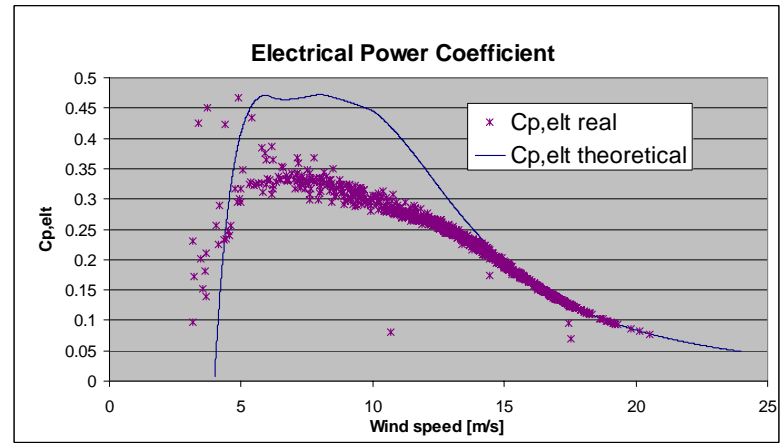

Fig. 2

\section{B. Mechanical Power Coefficient}

From the strip theory ${ }^{[2]}$ has been calculated the Mechanical Power Coefficient (eq. 3) and the Torque Coefficient (eq. 10).

$$
C_{p, m}(\lambda, \beta)=\frac{P m}{0.5 \cdot \rho \cdot V^{3} \cdot \pi \cdot \frac{D^{2}}{4}}
$$

$\mathrm{P}_{\mathrm{m}}=$ Mechanical Power
Airstream around the Turbine

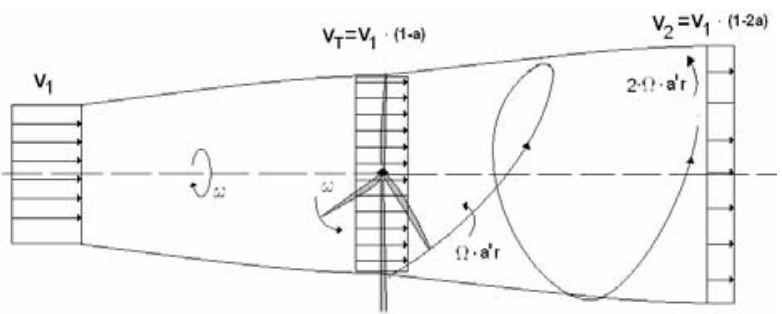

Fig. 3

$$
\begin{array}{ll}
k=1-2 \cdot a & a=\text { induced speed } \\
h=1+2 \cdot a^{I} & a^{I}=\text { rotational induced speed }
\end{array}
$$

Triangle of Speed at the Blade

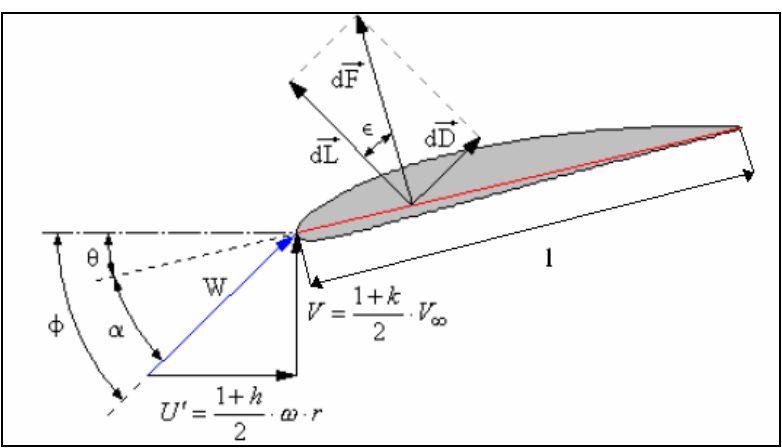

Fig. 4

Where:

$$
\begin{aligned}
& d L=\frac{1}{2} \cdot \rho \cdot C_{L} \cdot W^{2} \cdot l \cdot d r \\
& d D=\frac{1}{2} \cdot \rho \cdot C_{D} \cdot W^{2} \cdot l \cdot d r
\end{aligned}
$$

$\mathrm{C}_{\mathrm{L}}=$ lift coefficient

$\mathrm{C}_{\mathrm{D}}=$ drag coefficient

The curves of $C_{L}$ and $C_{D}$ (Fig. 5) haven been taken from Airfoil Naca 63-415 experimental data.
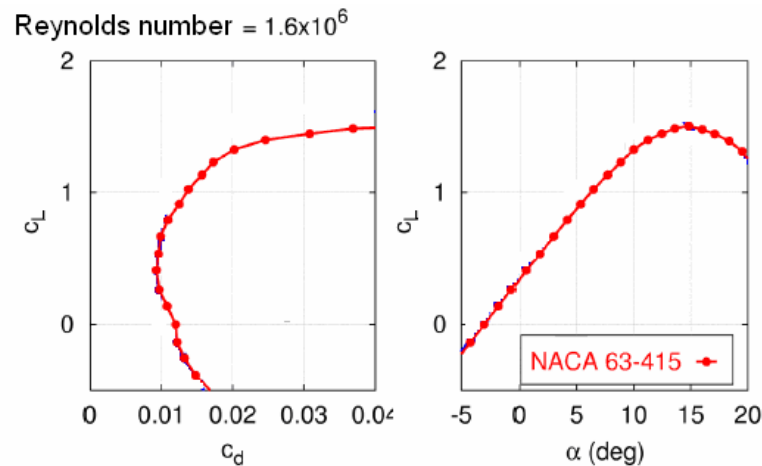

Fig. 5

The Fig. 6 shows the mechanical power coefficient calculated by strip theory, with the real dates of the wind turbine. 


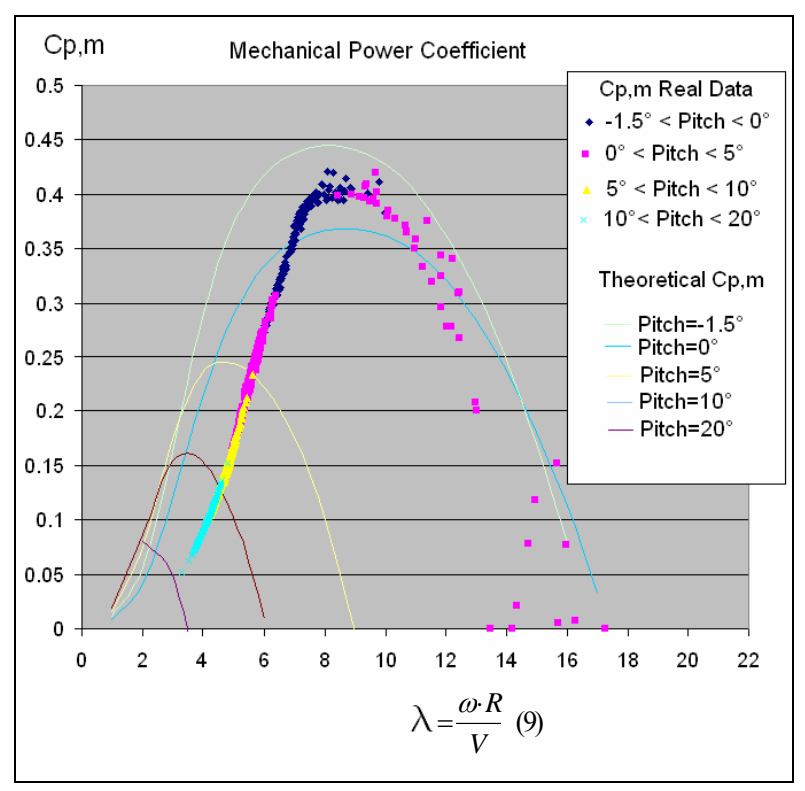

Fig. 6

$\lambda=$ tip speed ratio

$\mathrm{R}=$ radius rotor blade

$\mathrm{V}=$ wind speed

\section{Torque Coefficient}

$$
C_{q}=\frac{T \text { (torque) }}{0.5 \cdot \rho \cdot V^{2} \cdot \pi \cdot \frac{D^{3}}{8}}
$$

Comparison of the torque coefficient calculated by strip theory, with the real torque coefficient (Fig. 7).

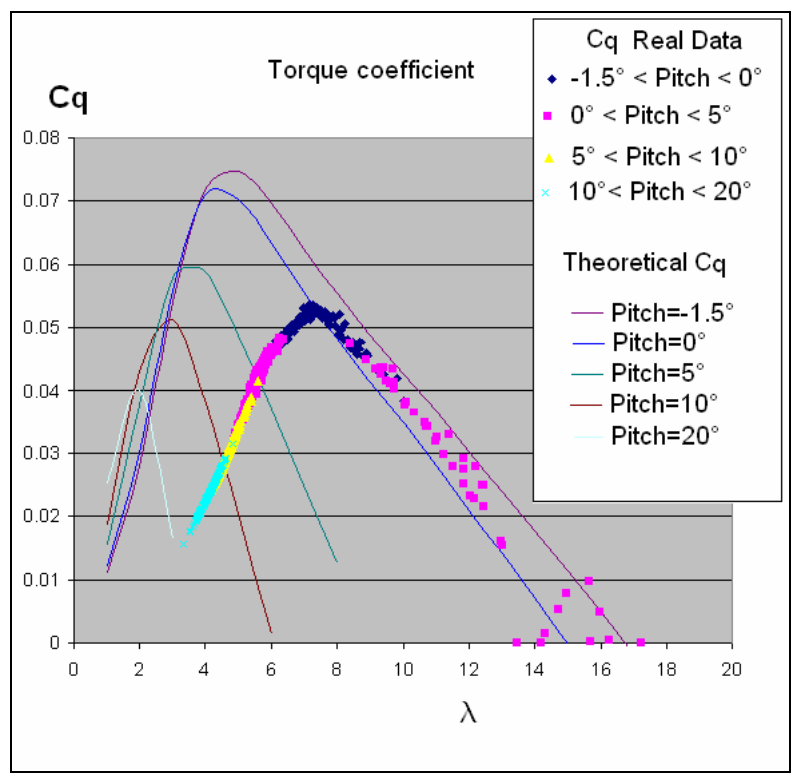

Fig. 7
The different between the curves could to be due to the following factors:

-strip theory use a criterion of optimal geometry shape of the blade

-coefficients $C_{L}$ and $C_{D}$ are calculated in a wind tunnel with different working conditions.

D. Characteristic Curves of the Wind Turbine of Variable Speed

Adjustment of the Blade Pitch Angle for the Power Control

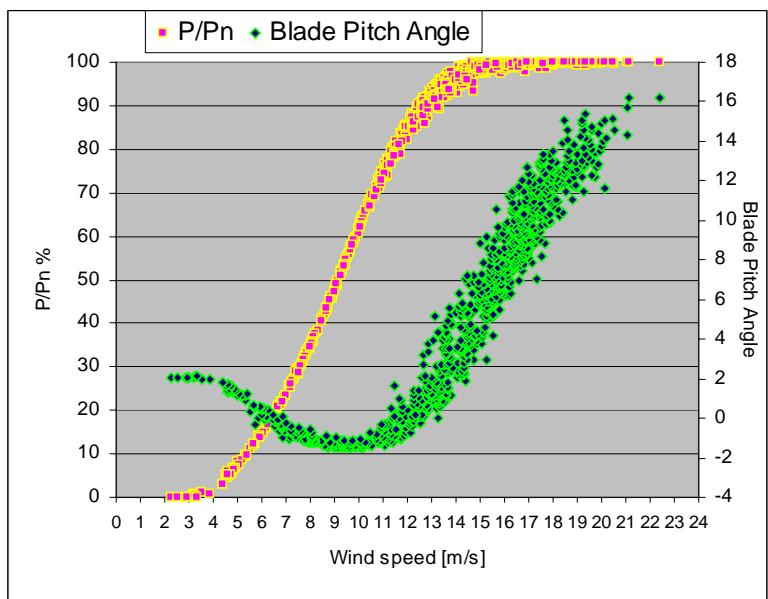

Fig. 8

Behaviour of Tip Speed Ratio and $\mathrm{C}_{\mathrm{p}, \mathrm{m}}$ in the Variable Speed Control

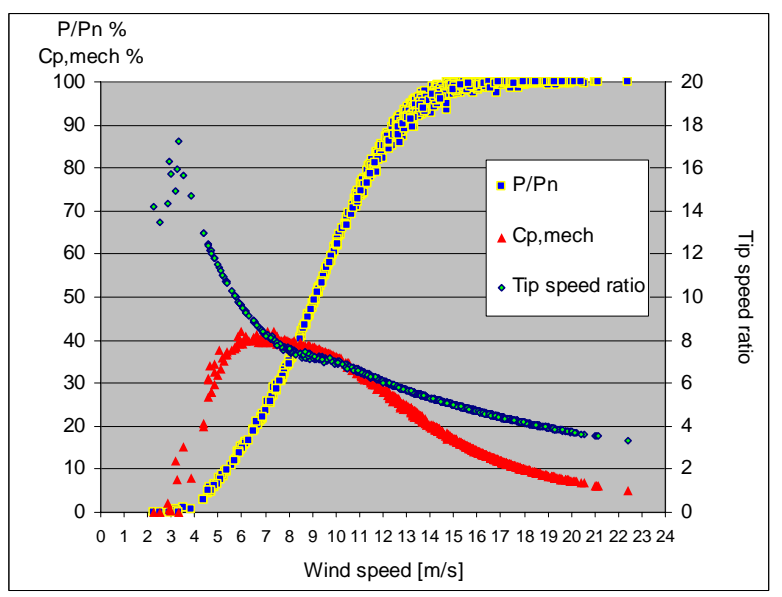

Fig. 9

The blade has a maximum power coefficient when the tip speed ratio $=7$. 


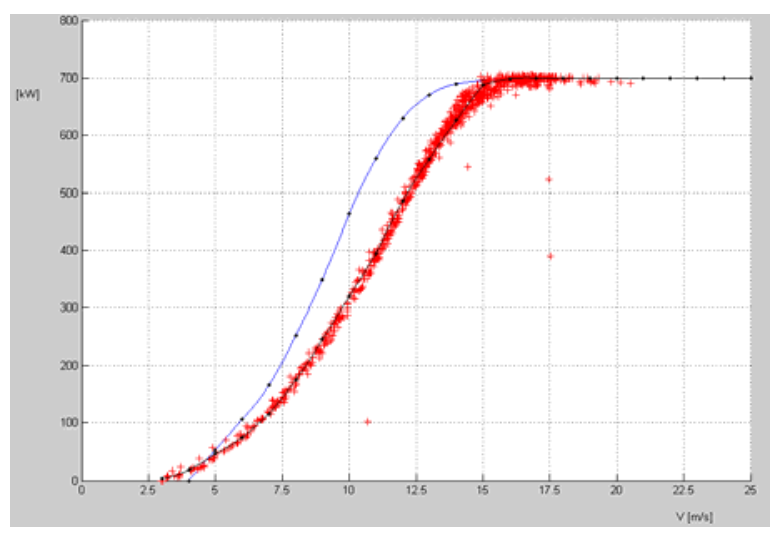

Fig. 10

The differences between real power curve and theoretical power curve (Fig. 10) could to be due to the following factors:

1. shade of the tower

2. different turbulence owed to the territory

3. different density of the air

4. different working conditions

5. different electrical and mechanical efficiency

\section{E. Weibull Distribution}

The parameters of Weibull distribution $\mathrm{C}$ y K define the wind distribution of the territory.

1. Weibull distribution function

$F(V)=e^{-\left(V_{0} / C\right)^{K}}$

2. Weibull probability density function

$f(V)=-\left.\frac{d F}{d V_{0}}\right|_{V_{0}=V}=K \cdot \frac{V^{K-1}}{C^{K}} \cdot e^{\left[-(V / C)^{K}\right]}$

Where: $\mathrm{K}=$ form factor

$\mathrm{C}=$ scale factor

Linear regression of wind dates has been used to calculate the parameters that define Weibull distribution.

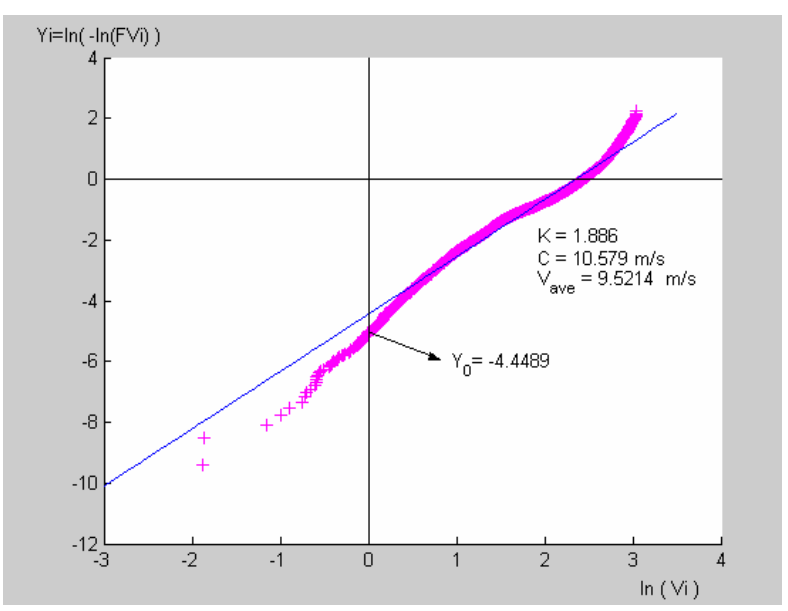

Fig. 11

\section{F. Produced Energy}

The energy is calculated by the follow equation:

$$
E=\sum_{i=0,2,4, \ldots, N-2}\left(\int_{V_{i}}^{V_{i+2}} p_{i, i+1, i+2}(v) \cdot K \cdot \frac{v^{K-1}}{C^{K}} \cdot e^{\left[-\left(v / C^{K}\right]\right.} \cdot 8760 \cdot d v\right)
$$

Where:

$\mathrm{p}(\mathrm{v})=$ polynomial that describes the power curve taking 3 working points at time (Fig. 11).

$$
p_{\left.\right|_{123}}(v)=\alpha_{1}+\alpha_{2} \cdot v+\alpha_{3} \cdot v^{2}
$$

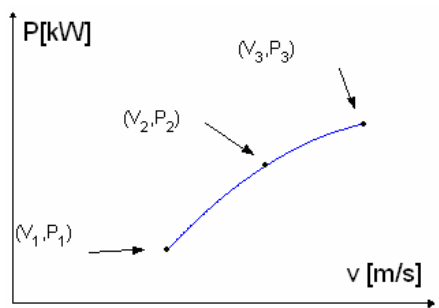

Fig. 11

The Fig. 12 represents the produced energy by the wind turbine, in a year, considering the curve of power of Fig. 1. 


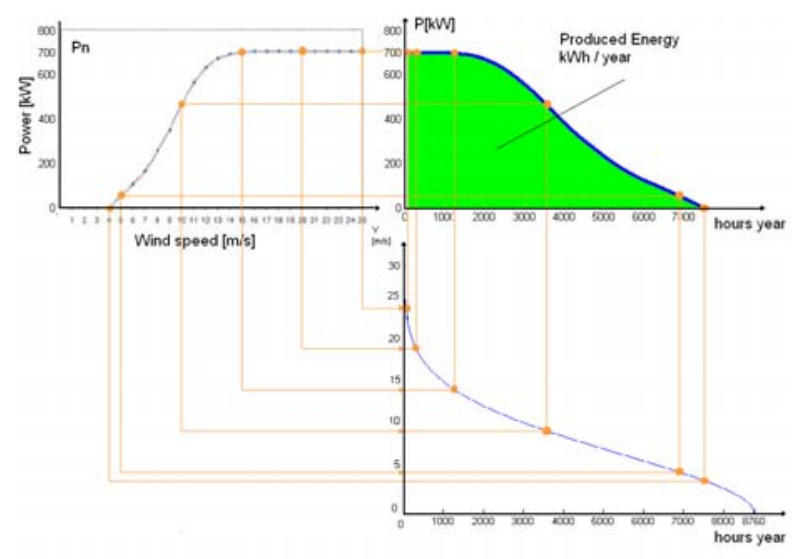

Fig. 12

The Fig. 13, it is graphic representation of different durability power curves to show the energy difference between the theoretical durability power curve and durability real power curve.

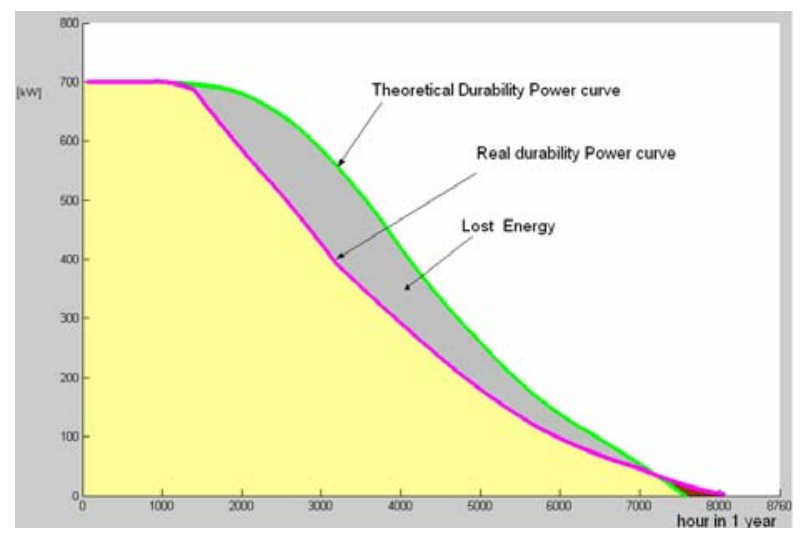

Fig. 13

The $15 \%$ of Energy is lost due to difference between the theoretical power curve and real power curve.

\section{Conclusions}

A series of real parameters of a Wind Park has studied and they have been compared with the theoretical parameters (separated 3 from the paper). The high efficiency of the Wind Park is verified with the obtained results.

\section{References}

[1] M. Helmer. Protections and Influence of Wind Farms from Wind Turbines and Grid Point of View. European Union Wind Energy Conference, 2-6 July 2001, Denmark .

[2] J.L. Rodriguez, J.C. Burgos, S. Arnalte.
Sistemas Eólicos de Produccion de Energia Electrica. Editorial Rueda, 2003.

[3] S.Heier. Grid Integration of Wind Energy Conversions System. John Wiley \& Sons, 1998. 